\title{
O IRDR E O REQUISITO DA EFETIVA REPETIÇÃO DE PROCESSOS (OU CAUSAS PENDENTES) QUE DEPENDAM DA SOLUÇÃO DA QUESTÃO COMUM DE DIREITO A SER UNIFORMIZADA ${ }^{1}$
}

\section{THE IRDR AND THE REQUIREMENT FOR EFFECTIVE REPETITION OF CLAIMS (OR PENDING CAUSES) THAT DEPEND ON THE SOLUTION OF THE COMMON QUESTION OF RIGHT TO BE UNIFORMIZED}

Aluisio Gonçalves de Castro Mendes Desembargador Federal no Tribunal Regional Federal da $2^{\mathrm{a}}$ Região (TRF-2); Professor Titular de Direito Processual Civil na Faculdade de Direito da Universidade do Estado do Rio de Janeiro (UERJ); Professor Titular de Direito Processual no Programa de Pós-Graduação em Direito da Universidade Estácio de Sá (UNESA); Especialista em Direito Processual Civil pela Universidade de Brasília (UnB); Mestre em Direito pela Universidade Federal do Paraná (UFPR); Mestre em Direito pela Johann Wolfgang Universität (Frankfurt am Main, Alemanha); Doutor em Direito pela Universidade Federal do Paraná (UFPR), em doutorado cooperativo com a Johann Wolfgang Universität (Frankfurt am Main, Alemanha); PósDoutor em Direito pela Universidade de Regensburg (Alemanha); Bolsista do Programa de Pesquisa Produtividade da UNESA; Diretor do Instituto Brasileiro de Direito Processual (IBDP); Diretor do Instituto Ibero-americano de Direito Processual; Membro da International Association of Procedural Law; Membro da Academia Brasileira de Letras Jurídicas (ABLJ). Rio de Janeiro/RJ. E-mail: aluisiomendes@terra.com.br

\footnotetext{
${ }^{1}$ Artigo recebido em 02/05/2021, sob dispensa de revisão.
} 
RESUMO: O presente texto discorre sobre a discussão em torno de um dos requisitos de admissibilidade do Incidente de Resolução de Demandas Repetitivas (IRDR), o da efetiva repetição de processos que dependam da solução da questão comum de direito a ser dirimida e que constitui o objeto do procedimento padrão. Para tanto, o autor estrutura o trabalho em duas partes. A primeira parte, relacionada ao processo legislativo, procura levantar o debate e a vontade final do legislador. A segunda parte trata da interpretação das normas legais pertinentes, cotejando-as também com o sistema, o propósito, a natureza jurídica e a lógica do novel instituto.

PALAVRAS-CHAVE: Incidente de Resolução de Demandas Repetitivas. Processo legislativo. Requisitos. Causas pendentes.

ABSTRACT: This paper deals with the discussion about one of the admissibility requirements of the Incident of Resolution of Repetitive Claims, the effective repetition of claims that depend on the solution of the common question of right to be uniformized and that is the object of the standard procedure. To this end, the author structures the paper in two parts. The first part, related to the legislative process, seeks to raise the debate and the final will of the legislator. The second part deals with the interpretation of the relevant legal norms, also comparing them with the system, the purpose, the legal nature and the logic of the new institute.

KEYWORDS: Incident of Resolution of Repetitive Claims. Legislative process. Requirements. Pending claims,

\section{O processo histórico de surgimento do Incidente de Resolução de Demandas Repetitivas (IRDR) no direito nacional}

A exposição histórica em torno da elaboração do instituto do Incidente de Resolução de Demandas Repetitivas é importante, especialmente por dois motivos. O primeiro, naturalmente, diz respeito à documentação e perpetuação de todo o processo prévio e legislativo que resultou na criação do IRDR. O segundo, que decorre do primeiro, está 
relacionado ao fornecimento de elementos que propiciem a melhor compreensão do instituto, a partir de uma interpretação autêntica e sistemática.

\subsection{A formulação da proposição na Comissão de Juristas, o (ante) projeto de novo Código de Processo Civil e o texto aprovado no Senado Federal}

O Incidente de Resolução de Demandas Repetitivas, como mencionado anteriormente, surgiu na Comissão de Juristas designada pelo Senado Federal para a elaboração do Anteprojeto de novo Código de Processo Civil. Logo no início dos trabalhos, sob a presidência de Luiz Fux, estabeleceu-se que cada integrante formularia proposições para serem debatidas. A proposta do instituto foi apresentada na Comissão por Paulo Cezar Pinheiro Carneiro, tendo recebido, inicialmente, a denominação de Incidente de Coletivização. A ideia, acolhida pela Comissão, buscava estabelecer um mecanismo que pudesse ser utilizado a partir da primeira instância, sempre que identificada controvérsia com potencial de gerar relevante multiplicação de processos fundados em idêntica questão de direito e de causar grave insegurança jurídica. Pretendia-se o fortalecimento do precedente, sucedendo, mas diferenciando-se, contudo, do incidente de uniformização de jurisprudência, do Código de Processo Civil de 1973.

No primeiro documento público em que foram expostas as proposições formuladas pela Comissão, o novo instituto já assumia uma posição de destaque:

Tendo como premissa esse objetivo, construiu-se a proposta de instituição de um incidente de coletivização dos denominados litígios de massa, o qual evitará a multiplicação das demandas, na medida em que o seu reconhecimento numa causa representativa de milhares de outras idênticas, imporá a suspensão de todas, habilitando o magistrado na ação primeira, dotada de amplíssima defesa, com todos os recursos previstos nas leis processuais, proferir uma decisão com largo espectro, definindo o direito controvertido de tantos quantos se encontram na mesma situação jurídica, trazendo 
uma solução de mérito consagradora do princípio da isonomia constitucional. $^{2}$

$\mathrm{O}$ texto acima poderia sugerir que o novo instituto seria semelhante ao Musterverfahren (procedimento-modelo) adotado na Alemanha no âmbito do direito público (nos ramos da Administração Pública e da Previdência e Assistência Social), que é processado e julgado, inicialmente, pelo próprio órgão de primeiro grau.

Em junho de 2010, veio a lume o texto do Anteprojeto de novo CPC, confirmando a inspiração alemã, mas dentro de um regramento significativamente mais próximo do sistema adotado para o Musterverfahren do mercado de capitais, introduzido com a Lei sobre o Procedimento-Modelo nos conflitos jurídicos do mercado de capital (Gesetz über Musterverfahren in kapitalmarktrechtlichen Streitigkeiten - KapitalanlegerMusterverfahrensgesetz - KapMuG), em 2005, como se pode observar na respectiva exposição de motivos:

Proporcionar legislativamente melhores condições para operacionalizar formas de uniformização do entendimento dos Tribunais brasileiros acerca de teses jurídicas é concretizar, na vida da sociedade brasileira, o princípio constitucional da isonomia. Criaram-se figuras, no novo CPC, para evitar a dispersão ${ }^{18}$ excessiva da jurisprudência. Com isso, haverá condições de se atenuar o assoberbamento de trabalho no Poder Judiciário, sem comprometer a qualidade da prestação jurisdicional. Dentre esses instrumentos, está a complementação e o reforço da eficiência do regime de julgamento de recursos repetitivos, que agora abrange a possibilidade de suspensão do procedimento das demais ações, tanto no juízo de primeiro grau, quanto dos demais recursos extraordinários ou especiais, que estejam tramitando nos tribunais superiores, aguardando julgamento, desatreladamente dos afetados. Com os mesmos objetivos, criou-se, com inspiração no direito alemão, ${ }^{19}$ o já referido incidente de Resolução de Demandas Repetitivas, que consiste na identificação de processos que contenham a mesma questão de direito, que estejam ainda no primeiro grau de jurisdição, para decisão conjunta. ${ }^{20} \mathrm{O}$ incidente de resolução de demandas repetitivas é admissível quando identificada, em primeiro grau, controvérsia com potencial de gerar multiplicação

${ }^{2} \mathrm{O}$ documento, subscrito pelo presidente da Comissão, Luiz Fux e datado de janeiro de 2010, encontra-se no link https://www.senado.gov.br/senado/novocpc/pdf/1a_e_2a_Reuniao_PARA_grafica.pdf (acessado em 03.11.2016). 
Revista Eletrônica de Direito Processual - REDP.

Rio de Janeiro. Ano 15. Volume 22. Número 2. Maio a Agosto de 2021

Periódico Quadrimestral da Pós-Graduação Stricto Sensu em Direito Processual da UERJ

Patrono: José Carlos Barbosa Moreira (in mem.). ISSN 1982-7636. pp. 01-21

www.redp.uerj.br

expressiva de demandas e o correlato risco da coexistência de decisões conflitantes. É instaurado perante o Tribunal local, por iniciativa do juiz, do MP, das partes, da Defensoria Pública ou pelo próprio Relator. O juízo de admissibilidade e de mérito caberão ao tribunal pleno ou ao órgão especial, onde houver, e a extensão da eficácia da decisão acerca da tese jurídica limita-se à área de competência territorial do tribunal, salvo decisão em contrário do STF ou dos Tribunais superiores, pleiteada pelas partes, interessados, MP ou Defensoria Pública. Há a possibilidade de intervenção de amici curiae. O incidente deve ser julgado no prazo de seis meses, tendo preferência sobre os demais feitos, salvo os que envolvam réu preso ou pedido de habeas corpus. O recurso especial e o recurso extraordinário, eventualmente interpostos da decisão do incidente, têm efeito suspensivo e se considera presumida a repercussão geral, de questão constitucional eventualmente discutida. Enfim, não observada a tese firmada, caberá reclamação ao tribunal competente. ${ }^{3}$

\footnotetext{
${ }^{3}$ Brasil. Congresso Nacional. Senado Federal. Comissão de Juristas, Código de Processo Civil: anteprojeto. Brasília: Senado Federal, 2010. Seguem as notas mencionadas na transcrição: "18 A preocupação com essa possibilidade não é recente. ALFREDO BUZAID já aludia a ela, advertindo que há uma grande diferença entre as decisões adaptadas ao contexto histórico em que proferidas e aquelas que prestigiam interpretações contraditórias da mesma disposição legal, apesar de iguais as situações concretas em que proferidas. Nesse sentido: "Na verdade, não repugna ao jurista que os tribunais, num louvável esforço de adaptação, sujeitem a mesma regra a entendimento diverso, desde que se alterem as condições econômicas, políticas e sociais; mas repugna-lhe que sobre a mesma regra jurídica dêem os tribunais interpretação diversa e até contraditória, quando as condições em que ela foi editada continuam as mesmas. $O$ dissídio resultante de tal exegese debilita a autoridade do Poder Judiciário, ao mesmo passo que causa profunda decepção às partes que postulam perante os tribunais" (Uniformização de Jurisprudência. Revista da Associação dos Juízes do Rio Grande do Sul, 34/139, jul. 1985). 19 No direito alemão a figura se chama Musterverfahren e gera decisão que serve de modelo (= Muster) para a resolução de uma quantidade expressiva de processos em que as partes estejam na mesma situação, não se tratando necessariamente, do mesmo autor nem do mesmo réu. (RALF-THOMAS WITTMANN. Il "contenzioso di massa" in Germania, in GIORGETTI ALESSANDRO e VALERIO VALLEFUOCO, Il Contenzioso di massa in Italia, in Europa e nel mondo, Milão, Giuffrè, 2008, p. 178). 20 Tais medidas refletem, sem dúvida, a tendência de coletivização do processo, assim explicada por RODOLFO DE CAMARGO MANCUSO: "Desde o último quartel do século passado, foi tomando vulto o fenômeno da 'coletivização' dos conflitos, à medida que, paralelamente, se foi reconhecendo a inaptidão do processo civil clássico para instrumentalizar essas megacontrovérsias, próprias de uma conflitiva sociedade de massas. Isso explica a proliferação de ações de cunho coletivo, tanto na Constituição Federal (arts. 5.o, XXI; LXX, 'b'; LXXIII; 129, III) como na legislação processual extravagante, empolgando segmentos sociais de largo espectro: consumidores, infância e juventude; deficientes físicos; investidores no mercado de capitais; idosos; torcedores de modalidades desportivas, etc. Logo se tornou evidente (e premente) a necessidade da oferta de novos instrumentos capazes de recepcionar esses conflitos assim potencializado, seja em função do número expressivo (ou mesmo indeterminado) dos sujeitos concernentes, seja em função da indivisibilidade do objeto litigioso, que o torna insuscetível de partição e fruição por um titular exclusivo" (A resolução de conflitos e a função judicial no Contemporâneo Estado de Direito. São Paulo: Revista dos Tribunais, 2009, p. 379-380).”
} 
A configuração inicial do IRDR revela a criação de um instituto novo, que, embora tenha recebido a inspiração alemã, assumia características próprias, com a conjugação de instrumentos nacionais e a introdução de aspectos genuínos.

No ordenamento brasileiro, pode-se assinalar que o Incidente de Resolução de Demandas Repetitivas complementa o sistema de julgamento de litígios seriados que foi inaugurado, respectivamente em 2006 e 2008, com os recursos extraordinários e especiais repetitivos. Estes mecanismos careciam de solução que propiciasse economia mais efetiva para toda a estrutura jurisdicional, em especial para o primeiro e segundo graus de jurisdição, que continuavam tendo que julgar de modo atomizado e anti-isonômico as demandas de massa e as questões comuns. Nesse sentido, o art. 848 do anteprojeto, na essência reproduzido no texto final do art. 928 do CPC, já apontava para um sistema de julgamento de casos repetitivos, ainda que algumas peculiaridades fossem mantidas para cada uma das espécies (IRDR e recursos repetitivos).

Em segundo lugar, o antigo Incidente de Uniformização de Jurisprudência era, de certo modo, sucedido pelo IRDR, no anteprojeto, e depois também pelo Incidente de Assunção de Competência (IAC). Mas, o projetado Incidente de Resolução de Demandas Repetitivas incorporava ainda a sistemática de outro mecanismo já conhecido do ordenamento jurídico brasileiro: o Incidente de Declaração de Inconstitucionalidade, especialmente no que dizia respeito ao procedimento de fracionamento do julgamento em duas fases: a) o órgão judicial fracionário ou de primeiro grau suscitariam o incidente e, depois de apreciado o seu mérito, efetuariam o julgamento do caso concreto; b) o órgão mais amplo do tribunal, inicialmente o plenário ou o órgão especial (na redação final, o que fosse definido pelo regimento interno), apreciaria a admissibilidade e o mérito do incidente, que seria concentrado na resolução da "questão jurídica", com a fixação da "tese jurídica". Por fim, haveria semelhança quanto à suspensão do processo, que ficaria aguardando a apreciação do incidente, e no efeito vinculativo do julgamento proferido no incidente, pois o órgão originário ficaria adstrito ao posicionamento adotado na resolução do incidente.

A técnica do incidente de declaração de inconstitucionalidade, na versão do IRDR, seria, contudo, ampliada nas suas potencialidades, principalmente quanto a dois aspectos: a) seria adotada também diante de processos que estivessem tramitando no juízo de primeiro 
grau; b) contra a decisão proferida no IRDR, caberia diretamente a interposição dos recursos especial e extraordinário.

O anteprojeto da Comissão de Juristas foi convertido no Projeto de Lei ${ }^{\circ} 166$, de 2010, tendo sido o teor do texto referente ao Incidente de Resolução de Demandas Repetitivas, praticamente, mantido ${ }^{4}$ na sua integralidade, na versão que foi aprovada, em primeiro turno, no Senado Federal.

\subsection{A versão do Incidente de Resolução de Demandas Repetitivas no texto aprovado na} Câmara dos Deputados 5

No substitutivo aprovado na Câmara dos Deputados, houve modificações significativas em relação ao texto anteriormente aprovado no Senado Federal.

A primeira dela foi quanto ao afastamento do caráter, de certo modo, preventivo, que estava presente na versão anterior, pois o incidente seria cabível "sempre que identificada controvérsia com potencial de gerar relevante multiplicação de processos". No texto da Câmara, passou-se a exigir "efetiva repetição de processos". Esta primeira mudança no texto, por si só, não ensejou maiores resistências, tanto que foi posteriormente mantida, como se verá oportunamente, na redação final aprovada no Senado Federal.

Houve significativa redução no campo de cabimento e de aplicação do Incidente de Resolução de Demandas Repetitivas em razão (a) da exclusão do juiz do rol de legitimados para suscitar o incidente; (b) do incidente somente poder ser provocado na pendência de processo no tribunal, afastando-se o cabimento do incidente enquanto não houver processo, tramitando no tribunal, que contenha a controvérsia sobre a questão comum de direito.

No que diz respeito à legitimação, se, por um lado, houve a exclusão do juiz de primeiro grau, por outro, a redação da Câmara ampliou a relação, para incluir a pessoa jurídica de direito público e a associação civil cuja finalidade institucional inclua a defesa

\footnotetext{
${ }^{4}$ Houve modificações tão somente na ordem e numeração de alguns artigos. Vide os artigos 895 a 906 do Anteprojeto e artigos 930 a 941 do Projeto n 166/2010, na versão aprovada no Senado.

${ }^{5}$ Sobre as duas versões, ou seja, a do Senado em primeiro turno e a da Câmara dos Deputados, vide BUENO, Cassio Scarpinella. Projetos de novo Código de Processo Civil comparados e anotados: Senado Federal PLS n. 166/2010 e Câmara dos Deputados PL n. 8.046/2010, São Paulo: Saraiva, 2014.
} 
do interesse ou direito objetivo do incidente. Esta ampliação, entretanto, não subsistiu na redação final aprovada no Senado Federal.

Importante acréscimo realizado na Câmara, mas que não perdurou no texto que acabou sendo chancelado no Senado, foi o da suspensão da prescrição em relação às pretensões pertinentes à questão de direito submetida ao IRDR. A previsão, como se verá oportunamente, que se encontra presente, com peculiaridades, também no procedimentomodelo do mercado de capitais no ordenamento alemão, parece ser uma peça importante dentro do sistema de julgamento de causas repetitivas, para que o incidente de resolução da questão comum possa alcançar o seu objetivo pleno. Se devidamente divulgada a sua pendência e a desnecessidade do ajuizamento das demandas repetitivas, em razão da suspensão do lapso prescricional, parece ser indubitável que a medida seria um grande estímulo no sentido de se conter o ajuizamento em massa durante a pendência do IRDR.

Por outro lado, na Câmara foram incorporadas importantes regras que acabaram se mantendo no texto definitivo, como: a) a da possibilidade de ser novamente suscitado incidente anteriormente inadmitido por falta de pressuposto, desde que este esteja presente na reiteração; b) a do descabimento do incidente quando a questão de direito já estiver afetada para decisão em recurso extraordinário ou especial repetitivo; c) a isenção de custas no IRDR.

Quanto ao prazo para o julgamento do Incidente de Resolução de Demandas Repetitivas, o lapso de seis meses foi ampliado para um ano, que se manteve na redação final, sendo, de fato, mais consentâneo com a realidade dos tribunais no âmbito nacional.

Por fim, mas não menos importante foi a inclusão feita na Câmara dos Deputados, no sentido de se estabelecer que a tese jurídica fixada a partir do julgamento do incidente seria aplicada a todos os processos que tramitem na área do respectivo tribunal, inclusive àqueles que tramitem nos juizados especiais do respectivo Estado ou região. (grifos nossos) A sugestão de inclusão, que foi apresentada pela Comissão Permanente de Processo Civil da Associação dos Juízes Federais (AJUFE), possui grande alcance, considerando o excessivo volume de processos que tramitam no âmbito dos juizados especiais ${ }^{6}$. Entretanto,

\footnotetext{
6 Os números são elevados. Somente em 2015, foram 6.360 .854 casos novos nos juizados especiais, representando 28,63\% do montante protocolado em primeiro grau. Dos processos pendentes em primeiro grau (68.475.728), no final de 2015, 7.763.123 estavam nos juizados especiais, representando $11,33 \%$ do total de processos no primeiro grau de jurisdição. Os dados são do Justiça em Números 2016, conforme link http://www.cnj.jus.br/programas-e-acoes/pj-justica-em-numeros, acessado em 15.11.2016.
} 
a proposta era mais ampla, pois atribuía aos próprios órgãos dos juizados especiais a competência para a apreciação do IRDR, compatibilizando-se, assim, com a respectiva estrutura e competência ${ }^{7}$.

\subsection{O IRDR na redação final aprovada no Senado Federal e no texto sancionado}

Cabe assinalar que a modificação mais sensível efetuada por ocasião da aprovação final no Senado Federal foi quanto à concepção pretendida pela Câmara dos Deputados, no sentido de condicionar o cabimento do Incidente de Resolução de Demandas repetitivas à existência de processo em tramitação no tribunal de segundo grau. Como já apontado, esta visão já se contrapunha ao anteprojeto redigido pela Comissão de Juristas, bem como à versão aprovada em primeiro turno no Senado.

Ressalte-se que o objetivo do IRDR estava focado na economia processual, na isonomia, na segurança jurídica e na busca da duração razoável dos processos. Em princípio, para que estes objetivos já pudessem se sentir, de modo mais direto, em todo o Poder Judiciário, pretendia-se a sua utilização de modo mais amplo, o que seria atingido se o incidente pudesse ser acionado mais rapidamente, ou seja, a partir da multiplicação em primeiro grau, sem a necessidade de se aguardar que chegassem aos tribunais de segundo grau, seja por força de ação originária ou de recurso.

O tema foi enfrentado, com destaque, no parecer final apresentado pelo Relator no Senado Federal ${ }^{8}$, concluindo no sentido de que:

Os $\S \S 1^{\circ}, 2^{\circ}$ e $3^{\circ}$ do art. 988 do SCD desfiguram o incidente de demandas repetitivas. Com efeito, é nociva a eliminação da possibilidade da sua instauração em primeira instância, o que prolonga situações de incerteza e estimula uma desnecessária

\footnotetext{
${ }^{7}$ A proposta era de que os órgãos equivalentes nos juizados especiais, tais como as turmas reunidas, no âmbito regional ou estadual, de acordo com a estruturação pertinente, ficassem com a competência para os Incidentes de Resolução de Demandas Repetitivas que fossem suscitados pelos órgãos dos juizados especiais, sem prejuízo da vinculação às teses fixadas pelos Tribunais Regionais ou de Justiça, quando matéria comum fosse afetada a estes órgãos.

${ }^{8}$ Trata-se do parecer final $n^{\circ}$ 956, de 2014, da Comissão Temporária destinada a estudar o Substitutivo da Câmara ao Projeto de Lei do Senado n ${ }^{\circ}$ 166, de 2010, que estabelece o Código de Processo Civil, cujo Relator era o então Senador Vital do Rêgo.
} 
multiplicação de demandas, além de torná-lo similar à hipótese de uniformização de jurisprudência.

Na verdade, os supramencionados ${ }^{9} \S \S 1^{\circ}$ e $2^{\circ}$, do art. 988 do Substitutivo da Câmara dos Deputados (SCD), foram, de fato, excluídos do texto, enquanto o $\S 3^{\circ}$ teve a sua redação deslocada para outro artigo e alterada, para reincluir o juiz no rol dos que poderiam suscitar o incidente.

Registre-se que houve a supressão de parte dos legitimados arrolados no dispositivo do substitutivo da Câmara (pessoa jurídica de direito público e associação civil cuja finalidade institucional inclua a defesa do interesse ou direito objeto do incidente) sem que houvesse motivação explicitada no parecer final subscrito pelo relator.

Duas outras significativas modificações foram sentidas no texto final, em relação ao teor do projeto aprovado na Câmara dos Deputados.

A primeira foi a que introduziu o parágrafo único no art. 978 do novo Código de Processo Civil. Estabeleceu-se que o órgão colegiado incumbido de julgar o incidente e de fixar a tese jurídica julgará igualmente o recurso, a remessa necessária ou o processo de competência originária. Este dispositivo vem sendo objeto de grande controvérsia, a começar pela sua constitucionalidade formal e material. No âmbito formal do processo legislativo, porque a norma não constava em nenhum dos textos anteriormente aprovados, respectivamente no Senado Federal ou na Câmara dos Deputados, embora, no parecer final, se tenha afirmado que já estivesse implícita na redação do SCD. Sob o prisma material, a norma afrontaria o disposto no art. 96, I, $a$, da Constituição da República, na medida em que esta teria previsto que compete privativamente aos tribunais a elaboração dos seus regimentos internos, dispondo sobre a competência e o funcionamento dos respectivos órgãos jurisdicionais e administrativos. É de se notar que o próprio parecer final do Senado, em referência a outro dispositivo ${ }^{10}$, foi enfático, ao afirmar que "desborda de seus limites

\footnotetext{
${ }^{9}$ A redação dos dispositivos era a seguinte:

" $\$ 1^{\circ} \mathrm{O}$ incidente pode ser suscitado perante tribunal de justiça ou tribunal regional federal.

$\S 2^{\circ} \mathrm{O}$ incidente somente pode ser suscitado na pendência de qualquer causa de competência do tribunal.

$\S 3^{\circ} \mathrm{O}$ pedido de instauração do incidente será dirigido ao presidente do tribunal:

I - pelo relator ou órgão colegiado, por ofício;

II - pelas partes, pelo Ministério Público, pela Defensoria Pública, pela pessoa jurídica de direito público ou por associação civil cuja finalidade institucional inclua a defesa do interesse ou direito objeto do incidente, por petição."

${ }^{10}$ No caso, o art. 991, §§ $1^{\circ}$ a $3^{\circ}$, do Substitutivo da Câmara dos Deputados. Vide parecer final, p. 179.
} 
quando invade, com muita intensidade, autonomia de organização interna do tribunal por meio do regimento interno". No plano material, porque a norma estaria em afronta ao art. 96, inciso I, da Constituição da República, que atribui privativamente aos tribunais a elaboração dos seus regimentos internos, dispondo sobre a competência e o funcionamento dos respectivos órgãos jurisdicionais. Portanto, não caberia ao CPC a fixação de competência interna dos tribunais.

A inconstitucionalidade do parágrafo único do art. 978 do CPC foi declarada, como preliminar, na apreciação do primeiro Incidente de Resolução de Demandas Repetitivas conhecido e julgado pelo Órgão Especial do Tribunal Regional Federal da $2^{\mathrm{a}}$ Região ${ }^{11}$. Interessante notar que, como boa parte dos tribunais, o TRF-2 também havia incorporado no seu regimento interno as normas do CPC. Sendo assim, o texto do próprio parágrafo único do art. 978 havia sido incluído na norma interna. Por isso, o Colegiado, percebendo a incoerência, resolveu tomar a iniciativa de provocar a alteração do regimento interno, que acabou sendo modificado, extirpando a anomalia e estabelecendo que caberia ao respectivo juízo natural, ou seja, o órgão incumbido do julgamento do caso concreto, efetuar a aplicação da tese firmada no IRDR, apreciando o recurso, a remessa necessária ou o pedido formulado.

\section{A controvérsia em torno da exigência de que o incidente tenha como base apenas processos já em tramitação no tribunal}

No decorrer do processo legislativo, ficaram caracterizadas duas nítidas concepções sobre a moldura de instituto que se pretendia construir, que correspondiam aos textos aprovados no Senado Federal e na Câmara dos Deputados. Em síntese, a concepção que predominou no Senado, tanto na versão aprovada em primeiro turno, quanto na redação final, foi no sentido de que o incidente poderia ser provocado quando houvesse processos em primeira instância ou no tribunal, razão pela qual o incidente poderia ser suscitado tanto pelo juiz de primeiro grau quanto pelo relator, assim como pelas partes, pelo Ministério Público e pela Defensoria Pública. No Substitutivo da Câmara dos Deputados, no entanto, constavam dispositivos que expressamente mencionavam a exigência de que, para ser suscitado, o

\footnotetext{
${ }^{11}$ Suscitado no proc. $\mathrm{n}^{\circ}$ 0004491-96.2016.4.02.0000, no tema ${ }^{\circ}$ 1, com IRDR admitido em 24.10.2016, julgado em 10.11.2017, com acórdão publicado em 04.05.2018, Rel. Des. Fed. Poul Erik Dyrlund.
} 
incidente deveria tomar como base processos que já estivessem em tramitação no tribunal de segundo grau e, por isso, o IRDR não poderia ser provocado pelo juiz de primeiro grau. Não obstante a clara manifestação a respeito, no parecer final que norteou o texto aprovado em última versão no Senado Federal, que foi sancionado e publicado, a controvérsia ainda persiste. Por certo, as duas posições encontram-se embasadas em fundamentos jurídicos sólidos e serão a seguir expostas.

\subsection{A posição de que o incidente somente pode ser suscitado na pendência de causa no tribunal}

O entendimento, no sentido de que o Incidente de Resolução de Demandas Repetitivas somente poderá ser suscitado com lastro em processos que já estejam tramitando no tribunal, possui, em termos de fundamento, algumas nuances, que serão expostas a seguir, de modo separado, por razões metodológicas.

\section{a) Competência dos tribunais de segundo grau fixada constitucionalmente}

$\mathrm{O}$ primeiro argumento seria de que os tribunais de segundo grau teriam a sua competência fixada em normas constitucionais, ou seja, no art. 108 da Constituição da República, para os Tribunais Regionais Federais, e nas Constituições Estaduais, por força da determinação contida no $\S 1^{\circ}$ do art. 125 da Magna Carta. Portanto, o Incidente de Resolução de Demandas Repetitivas, ou cláusula geral que pudesse abarcar esta possibilidade, deveria estar expressamente arrolado nos respectivos textos constitucionais.

Invoca-se ainda que a natureza incidental não afastaria a necessidade de previsão constitucional expressa, pois mesmo nestas hipóteses a Carta Federal teve a preocupação de arrolar a competência dos tribunais, como nos conflitos de competência entre juízes, cuja competência para os TRFs foi fixada no art. 108, inciso I, alínea $e$.

$\mathrm{Na}$ falta de previsão expressa, os tribunais somente poderiam conhecer dos incidentes pertinentes a processos que fossem da sua competência constitucional. A tese, de fato, é 
sedutora, tendo em vista o princípio consagrado do juiz natural. Entretanto, devem ser levados em consideração também outros aspectos.

Em primeiro lugar, o de que a competência dos tribunais de segundo grau não é matéria constitucional. Poderia ser considerada como matéria constitucional, no máximo, a organização e a competência do Supremo Tribunal Federal ${ }^{12}$.

No âmbito dos tribunais superiores, nem todos possuem a discriminação da sua competência na Constituição da República. No caso dos Tribunais Superiores do Trabalho, Eleitoral e Militar, a competência é fixada pelo legislador infraconstitucional ${ }^{13}$. A competência do Superior Tribunal de Justiça, de fato, é fixada na Constituição da República. Entretanto, o legislador já estabeleceu, mediante norma ordinária, a ampliação desta competência, fixando o denominado Incidente de Uniformização da Jurisprudência dos Juizados Especiais Federais (JEFs), nos termos do art. 14, § 4, da Lei $n^{\circ} 12.259$, de 12.07.2001. De modo similar, também foi instituído o pedido de uniformização de interpretação de lei na esfera dos Juizados Especiais da Fazenda Pública, perante o Superior Tribunal de Justiça, na hipótese do art. 18, $\S 3^{\circ}$, da Lei $n^{\circ} 12.153$, de 22.12.2009. Em ambas as hipóteses, os respectivos incidentes não estavam previstos expressamente no rol do art. 105 da Constituição da República e eram suscitados a partir do julgamento proferido por outros órgãos (Turma Nacional de Uniformização e Turmas Estaduais, respectivamente). Por sua vez, estes incidentes não foram declarados inconstitucionais, mas, pelo contrário, chancelados pelo Supremo Tribunal Federal, diante da necessidade de se preservar a segurança jurídica e da compatibilidade com as funções exercidas pelo Superior Tribunal de Justiça, justificando-se a utilização destes incidentes e da própria reclamação, em caráter excepcional, diante, na ocasião, da inexistência de procedimento semelhante no âmbito da Justiça Estadual $^{14}$.

\footnotetext{
${ }^{12}$ Mesmo assim, há ordenamentos constitucionais que permitem ao legislador ordinário o estabelecimento complementar das competências da Corte Suprema, como ocorre no art. 93 (2) da Lei Fundamental alemã.

${ }^{13}$ Nos termos dos artigos 113, 121 e 124, parágrafo único, da Constituição da República, respectivamente.

${ }^{14}$ Nesse sentido, RE 571572 ED, Relatora Min. Ellen Gracie, Tribunal Pleno, julgado em 26/08/2009, DJe223, RTJ, vol. 216-01, pp. 540, valendo destacar na ementa: "2. Quanto ao pedido de aplicação da jurisprudência do Superior Tribunal de Justiça, observe-se que aquela egrégia Corte foi incumbida pela Carta Magna da missão de uniformizar a interpretação da legislação infraconstitucional, embora seja inadmissível a interposição de recurso especial contra as decisões proferidas pelas turmas recursais dos juizados especiais. 3 . No âmbito federal, a Lei 10.259/2001 criou a Turma de Uniformização da Jurisprudência, que pode ser acionada quando a decisão da turma recursal contrariar a jurisprudência do STJ. É possível, ainda, a provocação dessa Corte Superior após o julgamento da matéria pela citada Turma de Uniformização. 4. Inexistência de
} 
Os Tribunais Regionais Federais possuem, de fato, a sua competência fixada na Constituição da República, nos termos do art. 108, bem como os Tribunais de Justiça nas respectivas Constituições dos Estados, conforme determinação do art. 125 , § $1^{\circ}$, da Carta Federal. Entretanto, o art. 108 da Constituição da República não especifica todos os incidentes cabíveis e apreciáveis pelos TRFs, concentrando-se principalmente nas causas originárias e nos respectivos recursos, modelo que, em regra, é adotado também nas Constituições Estaduais. Por isso, efetuou menção apenas ao conflito de competência entre juízes federais vinculados ao Tribunal, nos termos da alínea $e$, do inciso I, do art. 108 da Magna Carta.

No entanto, a Constituição Federal, assim como, em regra, as Estaduais, não previram, dentro da lista de competências dos TRFs ou dos TJs, outros incidentes, especialmente o de impedimento ou suspeição do juiz, ou mesmo de instrumentos criados ou fortalecidos mais recentemente, como a reclamação. No caso da recusa, pelo juiz, quanto à alegação de impedimento ou suspeição, o Código de Processo Civil de 1973 já previa a remessa ao tribunal da exceção, para julgamento, norma esta que nunca foi afastada, em razão dos fundamentos agora levantados em relação ao IRDR. No CPC-2015, o mecanismo deixou de ser chamado de exceção, sendo denominado expressamente de "incidente". Mas, em linhas gerais, seguindo-se o procedimento anterior, ou seja, não sendo o vício reconhecido pelo juiz, é remetido o incidente ao tribunal, nos termos do art. $146, \S 1^{\circ}$, parte final, que terá a competência para processar e julgar o incidente.

$\mathrm{O}$ argumento formal que nega a competência dos tribunais para o IRDR parece também não atentar para a existência de outras hipóteses, além do incidente de impedimento ou de suspeição do juiz, nas quais, de longa data, os tribunais de segundo grau passaram a receber atribuições delimitadas pela legislação infraconstitucional, em especial pelo próprio Código de Processo Civil. É o que ocorre, por exemplo, no julgamento per saltum, introduzido inicialmente no $\S 3^{\circ}$ do art. 515 do CPC-1973, a partir da Lei $n^{\circ} 10.352$, de 26.12.2001, e ampliado no CPC-2015, nos termos do art. 1.013, §§ $3^{\circ}$ e $4^{\circ}$. São hipóteses em

órgão uniformizador no âmbito dos juizados estaduais, circunstância que inviabiliza a aplicação da jurisprudência do STJ. Risco de manutenção de decisões divergentes quanto à interpretação da legislação federal, gerando insegurança jurídica e uma prestação jurisdicional incompleta, em decorrência da inexistência de outro meio eficaz para resolvê-la. 5. Embargos declaratórios acolhidos apenas para declarar o cabimento, em caráter excepcional, da reclamação prevista no art. 105, I, f, da Constituição Federal, para fazer prevalecer, até a criação da turma de uniformização dos juizados especiais estaduais, a jurisprudência do Superior Tribunal de Justiça na interpretação da legislação infraconstitucional.”. 
que, a rigor, o tribunal estará julgando o mérito da causa, sem que tenha havido o arrolamento expresso deste procedimento na lista da competência fixada constitucionalmente.

Diga-se, de certo modo, o mesmo em relação à reclamação, com a agravante (que deveria ser levantada pelos defensores da tese ora em comento) de que esta se encontra literalmente inscrita na competência do Supremo Tribunal Federal (art. 102, inciso I, alínea l) e do Superior Tribunal de Justiça (art. 105, inciso I, alínea f). No art. 108, entretanto, a ausência de previsão literal para a competência dos Tribunais Regionais Federais não parece excluir este tribunal, bem como os Tribunais de Justiça que não encontrem também a indicação da reclamação na respectiva Constituição do Estado, do alcance amplo da reclamação disciplinada nos artigos 988 a 993 do Código de Processo Civil de 2015.

Há ainda que se mencionar que, assim como os seus respectivos tribunais superiores, os tribunais de segundo grau, no âmbito da Justiça do Trabalho, Eleitoral e Militar, também não possuem as suas respectivas competências fixadas por norma constitucional, o que tornaria o fundamento formal ventilado desprovido de abrangência mais ampla, na medida em que o Incidente de Resolução de Demandas Repetitivas também pode ser, em tese, desde que preenchidos os requisitos, suscitado no processo trabalhista, eleitoral e penal (incluindose o militar).

Ressalte-se ainda que o Incidente de Resolução de Demandas Repetitivas é um mecanismo processual completamente novo no ordenamento nacional. Portanto, as Constituições, Federal e Estaduais, não poderiam prever algo inexistente ao tempo das respectivas promulgações.

Portanto, o Incidente de Resolução de Demandas Repetitivas deve ser visto sob uma ótica mais ampla e menos formalista, pois atende aos preceitos maiores da Constituição, especialmente o do acesso à justiça, da isonomia, da duração razoável dos processos, da economia processual e da segurança jurídica. As funções conferidas aos respectivos órgãos judiciais, no IRDR, por sua vez, estão em conformidade com a organização e com o sistema de competências estabelecidos na Carta Magna, dentro de uma concepção de uniformização regional ou estadual do Direito, encontrando o ápice nacional nos tribunais superiores.

Longe de afrontar, o novel incidente encontra a sua fonte maior na Constituição de 1988, considerando que o acesso à justiça, previsto no inciso XXV, deve guardar sintonia com os valores inscritos no caput do art. $5^{\circ}$, a começar pela igualdade, considerando que se 
trata de um direito não apenas individual, mas coletivamente considerado, como enunciado no seu Capítulo I, do Título II, dos direitos e das garantias fundamentais.

\section{b) O parágrafo único do art. 978 do Código de Processo Civil}

Parte da doutrina ${ }^{15}$ funda a defesa da tese restritiva, no sentido de que o IRDR somente poderia ser suscitado se houvessem processos já tramitando no tribunal e apenas a partir destes, com fulcro na regra enunciada no parágrafo único do art. 978 do Código de Processo Civil. Como este dispositivo estabelece que o órgão colegiado incumbido de julgar o incidente e de fixar a tese jurídica julgará igualmente o recurso, a remessa necessária ou o processo de competência originária, de onde foi suscitado o IRDR, defende-se a indispensabilidade da presença destes no tribunal, não apenas no momento do julgamento, mas da sua provocação.

A apreciação deste fundamento exige, contudo, uma análise da norma, contida no parágrafo único do art. 978, sob dois prismas: i) a sua constitucionalidade, formal e material; ii) o seu sentido e alcance.

O parágrafo único do art. 978 já foi objeto de comentário inicial, por ocasião da análise do processo legislativo, ressaltando-se que a sua redação, e sentido, não se faziam presentes em nenhuma das versões aprovadas inicialmente no Senado Federal ou na Câmara dos Deputados. Portanto, estaria formalmente contaminada pelo vício de inconstitucionalidade, em afronta ao disposto no art. 65 da Magna Carta, pois teria havido clara inovação no texto submetido unicamente à votação final e promulgação.

Em acréscimo, a regra parece conter também vício material, por invadir a competência legislativa interna privativa dos tribunais, para dispor sobre a competência e o funcionamento dos respectivos órgãos jurisdicionais, nos termos do art. 96, inciso I, alínea $a$, da Constituição da República.

Por último, ainda que a norma não estivesse contaminada pelos vícios supramencionados, restaria ainda a análise do seu conteúdo, sentido e alcance. Parece ser

\footnotetext{
${ }^{15}$ Nesse sentido: CÂMARA, Alexandre Freitas. O novo processo civil brasileiro, $3^{\mathrm{a}}$ ed., São Paulo: Atlas, 2017.
} 
evidente que se trata de uma norma de prevenção, provavelmente motivada pelo desejo de que a aplicação da tese em concreto seja realizada com a devida fidelidade, o que seria garantido, ou mais provável, se o mesmo órgão judicial realizar também o julgamento, em sede de competência recursal ou originária, do(s) processo(s) de onde se originou o IRDR. É claro que o IRDR pode ter se originado de processo já em tramitação no tribunal. De modo algum, se pretendeu afastar esta possibilidade, que decorre expressamente do sistema instituído, na medida em que pode ser instaurado pelo juiz ou relator (inciso I do art. 977), ensejando clara interpretação de que tanto os processos em tramitação perante a primeira instância quanto no tribunal poderão ensejar o pedido de instauração, pelo próprio órgão judicial ou pelos demais legitimados (incisos II e III do art. 977). O importante, contudo, parece ser que a existência eventual de uma regra de prevenção, no caso, não teria o condão de levar à conclusão de que apenas os processos em tramitação no tribunal poderiam ensejar a instauração do IRDR. Mas, sim, que naqueles instaurados a partir de processos em tramitação no tribunal, o órgão competente julgaria a tese e a causa em concreto, estabelecendo-se, assim, vis attractiva para a prevenção.

\section{c) O raciocínio dialético no sentido de que as questões jurídicas precisam estar mais maduras para serem sedimentadas e uniformizadas}

A escolha do modelo de procedimento padrão representa, por certo, mais uma discussão relacionada à política legislativa do que propriamente de interpretação. Registrese, como já exposto no cotejo com o direito estrangeiro, que, na Alemanha, foram estabelecidos dois sistemas, que ainda convivem, de Musterverfahren. O procedimento modelo vigente nos órgãos judiciais que julgam a matéria administrativa e de previdência e assistência social é realizado perante a primeira instância, sendo admitido que haja a suspensão de todos os processos, para que apenas um tribunal (de primeira instância) possa processar e julgar o Musterverfahren. No entanto, no sistema adotado para os litígios ocorridos no mercado de capitais, o órgão de primeiro grau, perante o qual houve o primeiro requerimento de instauração do procedimento-padrão, apenas realiza a admissibilidade, cabendo ao respectivo Tribunal de Justiça o julgamento dos Musterverfahren. 
A versão aprovada na Câmara dos Deputados estabelecia, como anteriormente mencionado, que o IRDR somente poderia ser suscitado quando os processos relacionados com a questão jurídica controversa já estivessem tramitando no âmbito do tribunal. Por certo, haveria, com exceção dos processos que chegassem ao tribunal em razão da sua competência originária, um debate prévio no primeiro grau de jurisdição, fazendo com que as causas já estivessem mais amadurecidas para o julgamento em segunda instância. No texto aprovado, esta possibilidade não se encontra descartada. Pelo contrário, ao tribunal cabe um juízo de conveniência a partir dos requisitos estabelecidos (efetiva repetição de processos e risco de ofensa à isonomia e à segurança jurídica), que poderá levá-lo a certa dilação quanto à admissibilidade do incidente, quando considerar que ainda não há uma quantidade tão significativa de processos ou que não se estabeleceu um risco significativo de ofensa à isonomia e à segurança jurídica. Mas, a opção legislativa foi claramente definida, no sentido de se priorizar a duração razoável dos processos, a isonomia, a economia processual e a segurança jurídica, que serão agasalhadas com a possibilidade de definição mais rápida da questão jurídica e com a técnica de concentração em torno desta.

Ressalte-se ainda que houve o estabelecimento de um procedimento especial, no qual se alargaram os espaços destinados ao debate, permitindo-se a atuação paralela dos interessados ${ }^{16}$ (pessoas, órgãos e entidades), a intervenção obrigatória do Ministério Público, a participação de amici curiae, a ampliação de prazos e a revisão da tese, além do cabimento eventual do recurso especial e extraordinário diretamente em relação ao IRDR. Tudo isso representa um espaço privilegiado de discussão em torno da questão jurídica, talvez muito mais amplo, profundo e democrático do que o de um simples caso individual, que poderia formar um precedente, até mesmo com caráter vinculativo, se incidente uma das demais hipóteses previstas no art. 927 do CPC.

\subsection{O Incidente de Resolução de Demandas Repetitivas pode ser suscitado a partir de causas em tramitação perante juízes de primeiro grau ou tribunais}

\footnotetext{
${ }^{16}$ Art. 983 do CPC.
} 
O novo Código de Processo Civil estabeleceu uma clara inovação, com a criação do Incidente de Resolução de Demandas Repetitivas, a partir de um sistema semelhante ao do Musterverfahren adotado na Alemanha para os litígios do mercado de capitais. Contudo, no modelo brasileiro, o tribunal de segundo grau decide apenas em relação à questão jurídica, fixando a tese respectiva, para que haja a apreciação dos casos concretos pelo juiz natural, ou seja, o órgão competente perante o qual tramita o processo, seja ele de primeira instância ou o próprio tribunal.

A opção representa uma opção política no sentido de considerar a gravidade dos problemas existentes, destacando-se o número excessivo de demandas repetitivas, o congestionamento de processos no Poder Judiciário, a demora no julgamento dos processos, a diversidade de pronunciamentos em torno de questões comuns, a necessidade de fortalecimento da isonomia e da segurança jurídica. A doutrina já apontava a necessidade do estabelecimento de mecanismos que propiciassem maior economia e segurança jurídica no âmbito de todo o Poder Judiciário e não apenas na esfera dos tribunais superiores. Por isso, a adoção de um instrumento que somente pudesse ser acionado quando os processos já tivessem alcançado os tribunais de segundo grau seria limitado quanto ao seu alcance e resultado.

O risco seria grande se houvesse a limitação pretendida na versão aprovada na Câmara dos Deputados. Isso porque haveria um requisito necessário, que poderia retardar a instauração do IRDR, a ponto de comprometer os seus objetivos. Ressalte-se que o novo procedimento se faz eficiente se for instaurado, processado e julgado dentro de um tempo razoável. Do contrário, poderá se prolongar uma situação patológica de quantidades imensas de processos suspensos indefinidamente, gerando instabilidade e descrédito em relação à prestação jurisdicional.

O mecanismo do IRDR aposta em uma solução a médio prazo, ou seja, a partir de uma técnica de gestão, na qual a suspensão dos processos poderá gerar economia. Presumese que os órgãos judiciais poderão se concentrar em outros processos. Em qualquer modelo eficiente de gestão, seria altamente questionável se todos os envolvidos se dedicassem concomitantemente às mesmas funções e atividades, sem que houvesse uma repartição mínima de trabalho. Embora a futura aplicação da tese jurídica firmada não represente uma aplicação mecânica, na medida em que se deverá analisar a adequação do caso fático à tese, 
a economia existirá se, de fato, os juízes não tiverem que se debruçar, todos, sobre as mesmas questões jurídicas. Se o IRDR, contudo, somente se torna admissível em momento posterior, quando os processos alcançaram os tribunais, a tendência é que os juízes já tenham despendido energias na análise das questões jurídicas controversas, com a elaboração de decisões e sentenças sobre a matéria, de modo que a economia será muito menor do que se poderia obter em um momento anterior.

Por outro lado, os efeitos de decisões proferidas em sede de tutela provisória, liminares ou de cumprimento de sentenças também poderão significar um risco muito maior de quebra da isonomia e da segurança jurídica, decorrente da maior demora na instauração e julgamento do Incidente de Resolução de Demandas Repetitivas.

A opção pelo julgamento concentrado não é peculiar apenas ao IRDR. Representa tendência, com as respectivas consequências, adotada pelo ordenamento brasileiro. Nesse sentido, podem ser apontados outros mecanismos, como o das ações diretas de inconstitucionalidade e de constitucionalidade, o mandado de injunção coletivo e individual, a arguição de descumprimento de preceito fundamental, os recursos repetitivos, o modelo de arguição de inconstitucionalidade nos tribunais e a criação da súmula vinculante do Supremo Tribunal Federal.

Por fim, há que se deixar claro que o IRDR deve ser suscitado e apreciado com lastro em causas que estejam pendentes, naturalmente, em razão do seu caráter incidental. Contudo, as causas poderão estar pendentes tanto no primeiro como no segundo grau de jurisdição, como ocorre, por exemplo, no incidente de impedimento ou suspeição de magistrados. O tema foi muito bem explorado em julgado ${ }^{17}$ proferido pela Terceira Turma do Superior Tribunal de Justiça, nos memoráveis votos proferidos pelos Ministros Marco Aurélio Bellizze Oliveira e Paulo Dias de Moura Ribeiro, que acompanharam o voto condutor da Ministra Nancy Andrighi.

\section{REFERÊNCIAS}

\footnotetext{
${ }^{17}$ O substancioso acórdão foi proferido no Recurso Especial no 1.631 .846 - DF (2016/0263354-4), julgado em 05.11.2019.
} 
BRASIL. Congresso Nacional. Senado Federal. Comissão de Juristas, Código de Processo Civil: anteprojeto. Brasília: Senado Federal, 2010.

BUENO, Cassio Scarpinella. Projetos de novo Código de Processo Civil comparados e anotados: Senado Federal PLS n. 166/2010 e Câmara dos Deputados PL $n$. 8.046/2010, São Paulo: Saraiva, 2014.

CÂMARA, Alexandre Freitas. O novo processo civil brasileiro, $3^{\text {a }}$ ed., São Paulo: Atlas, 2017.

CONSELHO NACIONAL DE JUSTIÇA. Justiça em Números 2016, conforme link http://www.cnj.jus.br/programas-e-acoes/pj-justica-em-numeros, acessado em 15.11.2016.

MANCUSO, Rodolfo de Camargo. A resolução de conflitos e a função judicial no Contemporâneo Estado de Direito. São Paulo: Revista dos Tribunais, 2009, p. 379380)

RALF-THOMAS WITTMANN. Il "contenzioso di massa" in Germania, in GIORGETTI ALESSANDRO e VALERIO VALLEFUOCO, Il Contenzioso di massa in Italia, in Europa e nel mondo, Milão, Giuffrè, 2008.

TRIBUNAL REGIONAL FEDERAL 2 $2^{\mathrm{a}}$ REGIÃO. Suscitado no proc. $\mathrm{n}^{\mathrm{o}}$ 000449196.2016.4.02.0000, no tema $\mathrm{n}^{\circ}$ 1, com IRDR admitido em 24.10.2016, julgado em 10.11.2017, com acórdão publicado em 04.05.2018, Rel. Des. Fed. Poul Erik Dyrlund. SUPERIOR TRIBUNAL DE JUSTIÇA. RE 571572 ED, Relatora Min. Ellen Gracie, Tribunal Pleno, julgado em 26/08/2009, DJe-223, RTJ, vol. 216-01.

SUPERIOR TRIBUNAL DE JUSTIÇA. Recurso Especial $\mathrm{n}^{\circ} 1.631 .846$ - DF (2016/0263354-4), julgado em 05.11.2019. 